\title{
Towards Earthquake Resistant Residential Neighborhood in China: Examination of vulnerability in outdoor spaces
}

\author{
Xue Ma, Ryuzo Ohno \\ Department of Build Environment, \\ Tokyo Institute of Technology, Japan \\ ma.x.ab@m.titech.ac.jp , rohno@n.cc.titech.ac.jp
}

\begin{abstract}
China is a seismic active country. We suffered a large number of fatalities by earthquake damage. Agreat deal of requirements on disaster mitigation has been putting forward and which is becoming a hot topic in the society. This paper focuses on the safety situation of residential environment in Chinese cities, tries to examine the vulnerabilities for earthquakedisaster mitigation. Wechose the city of Tianjinastargetarea applying for the detail analysis. An evaluation was interpreted into suggestions and advices on planning and management.
\end{abstract}

Keywords: Vulnerability, Earthquake disaster mitigation, Residential area

eISSN 2514-751X @ 2018 . The Authors. Published for AMER ABRA cE-Bs by e-International Publishing House, Ltd., UK. This is an open access article under the CC BY-NC-ND license (http://creativecommons.org/licenses/bync-nd/4.0/). Peer-review under responsibility of AMER (Association of Malaysian Environment-Behaviour Researchers), ABRA (Association of Behavioural Researchers on Asians) and cE-Bs (Centre for EnvironmentBehaviour Studies), Faculty of Architecture, Planning \& Surveying, Universiti Teknologi MARA, Malaysia.

DOI: https://doi.org/10.21834/aje-bs.v3i7.259 


\subsection{Introduction}

China locates in one of the most seismically active regions of the world. Since the beginning of the last century, we have had nearly 800 quakes with a magnitude of over 6 on the Richter scale and suffered a large number of fatalities by earthquake damage, the stricken area covers over 300,000 square kilometers and more than 7 million destroyed rooms. It put forward a great deal of requirements on disaster mitigation especially after the 2008 Wenchuan Earthquake.

\section{Background}

As an earthquake active country, earthquake threatened most of the Chinese cities more or less. Earthquakes have happened in almost all the provinces, municipalities and regions except in the province of Guizhou, Zhejiang. How to improve the capability of disaster-resistant in China comes as primal issue nowadays. Two features of damage caused by earthquakes in China are most dominant: one is large number of fatalities caused by low building quality and low evacuation efficiency. The other one is slow recovery after earthquake caused by lacking of emergency responding system and rescue system, taking too long time taken in rebuilding.

\section{Current System in Chinese City}

Based on those features, this research mainly focuses on the urban evacuation system starting with developing a method for examining vulnerability in residential area.

The urban disaster mitigation system in China is still unenlightened and insufficient even after experienced several big earthquake recent years. The current existing evacuation system in Chinese cities is mainly for war and locates in the underground spaces. The evacuation spacesagainst natural disasters are quite limited. Once an earthquake happens there is seldom specific evacuation route and space to orient citizens evade from the dangerous areas.

\subsection{Vulnerabilities of Chinese City For Earthquake Disaster}

According to the physical and social conditions, different urban situations bring different requirements to urban construction. Different cities may face different potential vulnerabilities when an earthquake happens, so the demands on disaster mitigation system will be diverse also.

Using the Japanese cities which possess a well developed disaster mitigation system as a comparison, the contrast between a Japanese city and a Chinese city obviously shows the different characters, reflects the weaknesses and requirements of earthquake disaster mitigation in China.

\section{Characteristics of Chinese Cities}

There are several significant differences in the Characteristics of Chinese cities which are shown in the table 1 . Chinese cities is more likely to use wide avenues dividing urban area 
into easily-recognizable super blocks while the Japanese cities use narrow and dense streets consists a continuous road pattern. Since most of the residential buildings are concrete or brick multi-layer and fireproof in China rather than wooden frame houses in Japan, the dangers caused by an earthquake comes from the threats of buildings collapsing and the falling of debris.

Table 1: Characteristics of Urban Areas in China and Japan

\begin{tabular}{|c|c|c|}
\hline Characteristics & China & Japan \\
\hline $\begin{array}{l}\text { Building structure in vulnerable } \\
\text { urban areas }\end{array}$ & e Concrete/brick & Wooden-frame \\
\hline type in vulnerable urban areas & 6 floors/ high-rise $(>18)$ & Low-rise $(<10)$ \\
\hline City Road pattern & $\begin{array}{l}\text { e avenue divide urban area into } \\
\text { superblock }\end{array}$ & $\begin{array}{l}\text { Continuous pattern consist by dense } \\
\text { and narrow street }\end{array}$ \\
\hline Evacuation spaces system & Unplanned and inadequate & Planned \\
\hline Concerned dangers & $\begin{array}{l}\text { Building collapse Debris } \\
\text { Safety during evacuation }\end{array}$ & Spreading of fire Building collapse \\
\hline
\end{tabular}

Source: (Xue Ma, 2011)

\section{Characteristics and Vulnerabilities of Residential Area in China}

We can classify the residential area into different types by multiple standards, such as area location, building density, building structure, layout and others. Depending on a building condition in different cities or regions, the demarcation method shifts. The distribution of residential areas in Chinese cities is in residential sites with certain boundaries and occupies an area under 15ha. Most of the residential sites enclose with a fence or baluster except for the traditional residential ones.

We can distinguish the residential buildings by their build year especially in large cities. Most of the residential buildings between 1960s - 1980s are brick structure, $1-2$ floor courtyard houses. This traditional courtyard-housing widely locates in the whole country and more or less preserved in the big and medium cities, it takes dominant in most of the small cities. The building built after the 1980s are multi-layer brick or concrete structure. Since the buildings before the 1990s are without a reliable earthquake-resistant code, building structure is the biggest threat item.

After the 1990s the new code for buildings and planning debuted, with both the earthquakeresistance level and construction standards enhanced. The high-rise residential building has risen into people's horizon with high building quality and high capability. On the other hand, the building management took a new step, there are usually have a certain company running the management office, the residents need to follow certain ordinance maintaining the public living environment.

There are also a small number of special residential buildings, for instance: the concession area built before the 1900s, and some industrial reforming buildings as well as most recent prevailing low-rise housing in the suburban area. 

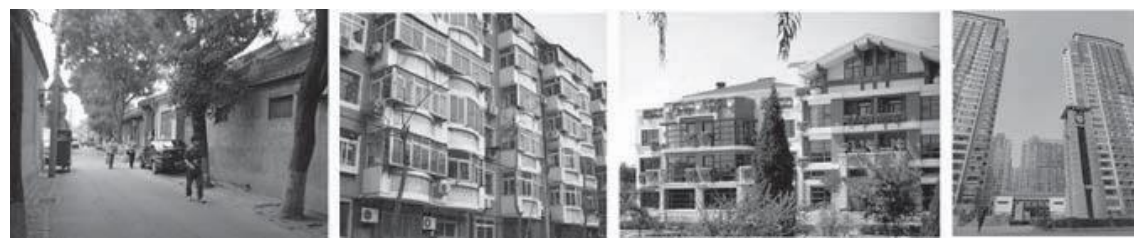

Figure 1: (a) Traditional House; (b) Middle-Rise Building before 1990; (c) Middle- Rise Building after 1990; (d) High-Rise Building

\subsection{Examination Method of Vulnerabilities}

We try to detect the vulnerable areas by examining urban elements in different scales. We classify the urban elements into 5 categories according to the scales: the buildings, the neighborhood, the community, the superblock, and the city. Urban area possesses various uses, such as a commercial area, industrial area, high-rise residential area, low-rise residential area, etc. The requirements on disaster mitigation are not coherent due to the different road patterns and building types relating to the land use. The commercial area may face less risk during night time but require higher on day time than residential area. Here, the discussion is more likely based on the residential area which brings forward more problems on taking refuge both temporary and long-term.

\section{Detect Vulnerabilities by Urban Texture}

With the bigavenues dividing theurbanareas intohighly-recognizable super blocks, the spaces inside one super block or between several super blocks usually shows a similar road-pattern, building density and building size even building height. These features represent a certain urban texture. The external information such as building history or culture background also brings a great amount of influence on building quality, earthquake- resistance standard and aging of structures. We can easily recognize the differences by the urban texture and divide the urban areas into different types of super blocks.

\section{A Simple Method for Evaluation of the Dangers}

We chose samples from typical super blocks for analysis in a detailed scale. We try to utilize a uniform criterion which reflects on the features and requirements most directly to evaluate the vulnerabilities inside different types of super blocks, so we bring the concept of Circulation Spaces as the criterion for evaluation of vulnerabilities. Circulation combines evacuation and access actions, it means free movement or passage in a circuit in side particular area which contains getting off, getting in and staying. Circulation spaces also contain the spaces for temporary material supply especially. In this research, analysis also includes estimating all the available public spaces both for evacuation and gathering.

\subsection{Case Study in the City of Tianjin}

We took the city of Tianjin, China applying for the real case study. The city is $120 \mathrm{~km}$ away 
from capital Beijing, it has $11,917.3 \mathrm{~km}^{2}$ occupied area with 11,76 million population which experienced over 140 earthquakes over magnitude 4.7 , and 5 big earthquakes over magnitude 7 including the 1976 Tangshan earthquake with over 250,000 fatalities. Five typical residential patterns are distinguished by different urban texture and historical background, they are: high-rise building area (HB), new middle-rise area (NM), old middle-rise area (OM), historical concession ( $\mathrm{HC}$ ) area and Traditional Neighborhood (TC) area. One residential site around 8ha in Chinese standard was chosen as a sample for applying the method for each area.
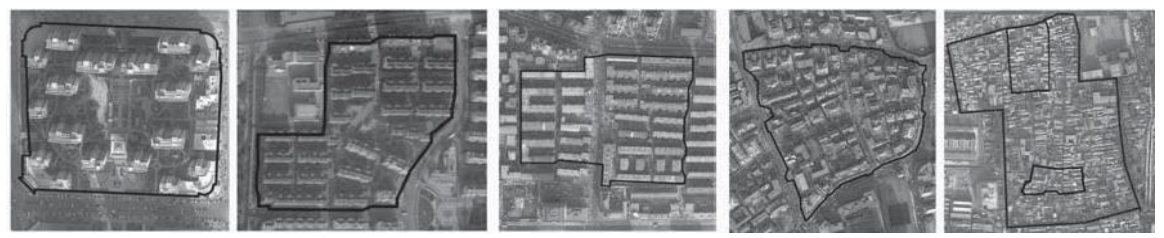

Figure 2: Typical Residential Area in Tianjin

(Left to right: A High-rise building after 2000, B Middle-rise building after 2000, C Middle rise building after 1980, D Concession housing before 1900,

E Traditional housing before 1970)

Source: (GeoEye-1 Satellite image, 2011)

\section{Field Survey on Target Area}

We conducted a field survey in the chosen area. In this survey, we observed all the trivial elements in each particular area which track records both original building information and environment situation affected by human behavior. We divided the observation target into 4 parts: buildings, inside road, outside road and plants. A check list accompanied with a detailed route map which lists out observation points within each group consisting of Possible debris I Roof style of the buildings / Special function building or space/Road block/Lane (inside road) / Grass and Tree / Dangerous facility/ Green belt / Tree species / Stair well / Accessibility of the whole area.

\section{Characteristics of Different Types of Residential Area}

The High-rise building built with a concrete-steel frame structure is in a very low possibility of collapse when an earthquake happens. The debris of the building is the most threatening issue concerning evacuation especially when its façade decorates with large windows and glass. The higher the building is, and the bigger the shaking is, the larger the affected area will be. The chosen High-rise building site is one of the classic layouts in a Chinese city. A wide concentrated space locates in the middle while the boundary connects and encloses by commercial buildings, the separation of pedestrians and vehicles allows the car to get in only for emergency situations, with one ring road and 2 entrances which are wide enough for cars to pass through. The car parking spaces locates in the underground of the whole area including the center open spaces. This may raise some concerns on the structure safety of the ground floor. A kindergarten and a large power station lay on the north-east part of the 
area.
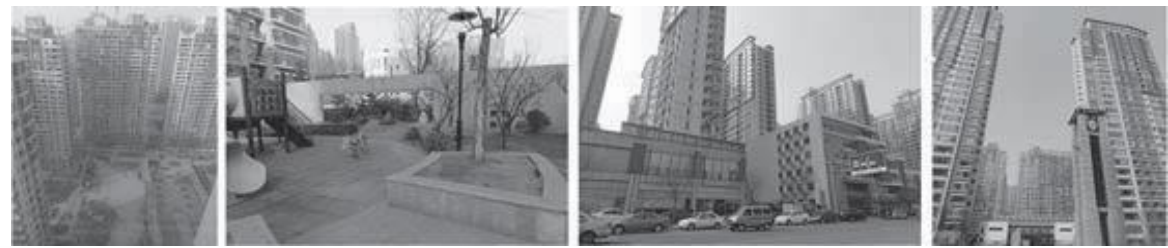

Figure 3: High-rise Building Area

Source: (Xue Ma, 2011)

The new Middle-rise building is the buildings under 21 meters and built after the 1990s, which structure is concrete shear wall, with low possibility of collapse. The New Middle-rise building area is strictly restricted by the planning guidelines on spaces between the buildings and the environment. The chosen site is semi-enclosed, where entrances can be found in all directions. The buildings are arranged parallel. Illegal constructions and unreasonable utilization of the balcony raise the danger for possible debris. Vehicles and pedestrians are mixed, which leads to lots of illegal parking, with cars and bicycles randomly parked on streets which blocks the evacuation routes.
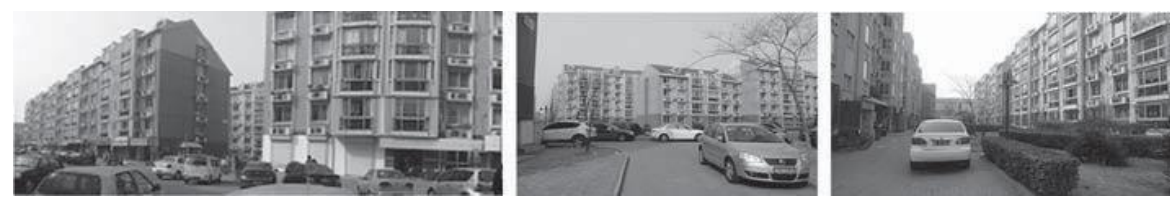

Figure 4: New Middle-rise Building Area

Source: (Xue Ma, 2011)

Old Middle-rise building area is in contra with the new middle- rise building area where its masonry structure built before the 1990s. The structure is inferior compared with the New Middle-rise area. The layout of Old Middle-rise building area resembles with the New Middlerise building area but is not confined by the new guidelines. Besides the common weaknesses of middle-rise building area, such as illegal parking and constructions, the most distinct feature of the chosen site is the poor construction of the infrastructure, such as the high-risk overhead pipes. Also the onlyentrance is narrow which increasesthe difficulty for evacuees. Because of the lack of management measures, the sanitation conditions are unsightly, the garbage and waste stores excessively, invasion of public spaces is also quite popular, residents use the greenbelt as private gardens or storerooms, abandoned furnishings and bicycles take the space of parks. 

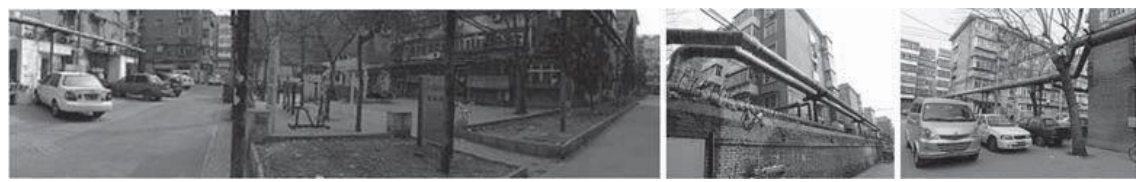

Figure 5: Old Middle-rise Building Area

Source: (Xue Ma, 2011)

Concession area built before 1900 by European architects is one of the representational areas of Tianjin. Low-rise buildings take advantages of chosen site. The buildings still stay in good quality, enough spaces between buildings compose a scale-friendly environment. The whole site openly connects with urban road system but the fences and walls divide the blocks into small yards which may decrease the options for evacuation routes.
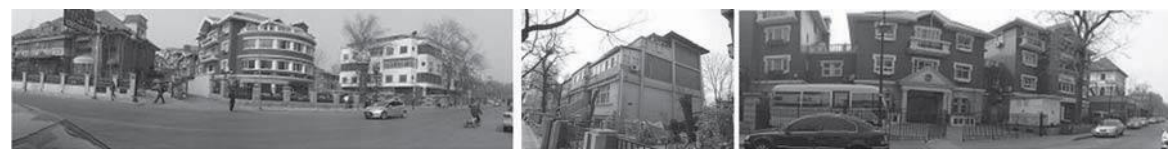

Figure 6: Concession Area

Source: (Xue Ma, 2011)

Traditional Neighborhood is the brick houses built around the 1960s. Both the building quality and spatial arrangement are facing huge dangers from earthquake damage. The buildings are not restricted by any construction code, with high possibility of building collapse and falling of debris. After years of corrosion, the building's fragility exceeds all the other areas. Illegal buildings with an even lower quality appear everywhere. The streets of Traditional Neighborhood area are extremely narrow and blocked by garbage and obstacles. Most of the area is not wide enough for vehicles.
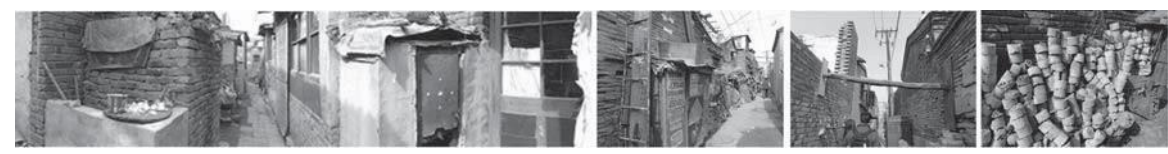

Figure 7: Traditional Neighbourhood Source: (Xue Ma, 2011)

\section{Evaluation on the Vulnerabilities by Circulation Spaces}

To provide a numerical description of each target area to figure out the degree of severity of vulnerability, we use a measurement method to evaluate the danger issue.

After choosing target area, we draw network diagram showing all possible circulation routes on the site plan in order to measure circulation spaces. Firstly, we identify the spaces where the junctions of network exist and draw circles of maximum size that fit into the identified spaces. Then the centre of circle is defined as a node of circulation route. Between 
two adjacent nodes, we draw circles of maximum size in the inflection point fit the spaces between buildings. With this method, we can describe the changing width of circulation spaces along the routes.
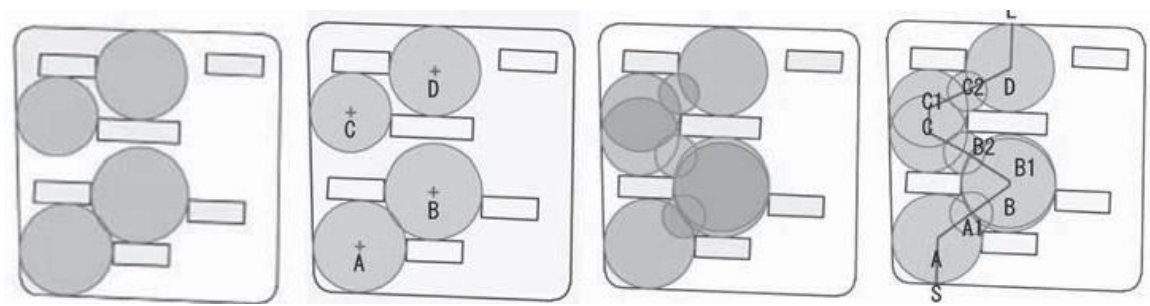

Figure 8: Procedure for Measure the Circulation Spaces

Source: (Xue Ma, 2011)

\section{Analysis on different damage situation}

The analysis bases on the map information in terms of buildings and spaces without the elements involving in previous field survey. We measure the circulation routes by category of radius which set as every 3 meters difference to record the length of the route that belongs to each radius category

Take the situation of surface damage and structure damage into our consideration, debris drop from the buildings has an uncertain area of effect. We assume that the width of surface damage effecting area is $10 \%$ of building's height, the width of heavy damage effecting area is $30 \%$ of building's height, judge if each circulation route works. The surface damage only makes little influence but heavy damage could trigger bigger influence on the analysis of most area.

Area $H B(A)$ possesses the widest circulation path. It changes a lot when heavy damage happen with only very limited but wide spaces in the center of the area left. Area NM (B) performs best in all areas, the circulation spaces won't reduce when surface damage happens and only changes a little when heavy damage happens. The tendency of area OM

(C) is similar with area NM but the influence of heavy damage presents a distinct danger. Its length exceeds almost $1 / 3$ more than area NM by $2300 \mathrm{~m}$. The HC (D) area shows a dense pattern with more than $2800 \mathrm{~m}$ length. The width of circulation route is less than $17 \mathrm{~m}$ which changes a lot more than those areas mentioned above under damage situation. The TN $(E)$ area is quite special compares to all the other areas. It shows extremely dense and long circulation space. Even the biggest radius is less than $5 \mathrm{~m}$ while the total length reaches almost $5000 \mathrm{~m}$. 

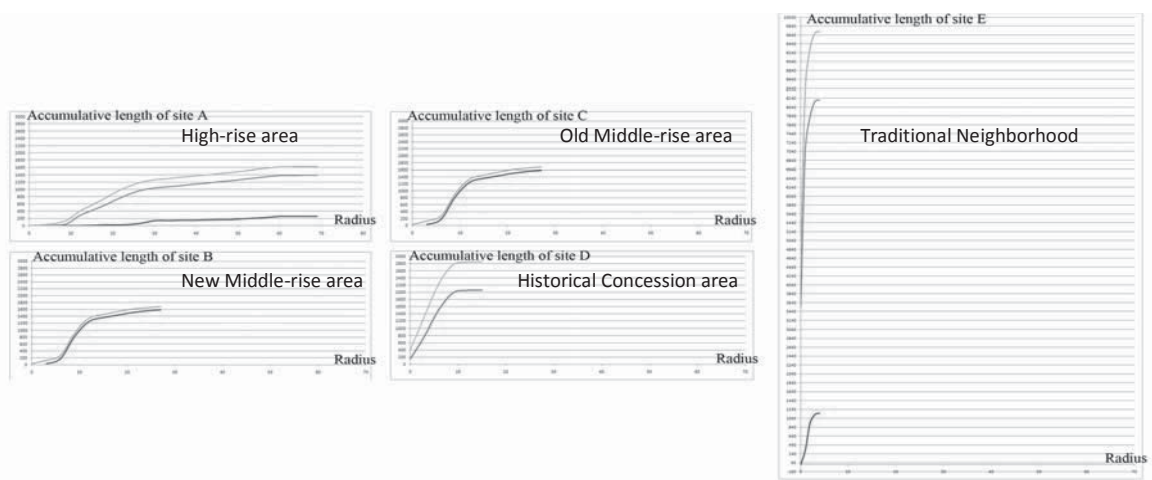

Figure 9: Accumulative Length of Circulation Spaces under Different Damage Situation Source: (Xue Ma, 2011)

\section{Analysis on usable spaces}

Some circulation spaces wider than certain width are also important, such as the shelter for people gathering, the space for collecting and distributing emergency goods, and wide road for fire engines access which is significant towards indoor fire and trapped person. We set 4 meters (the minimal width for fire engine), 9 meters (two lanes for vehiclesaccording to the index) and 18 meters separately as three standards to measure the available spaces.

The comparison of available spaces under different damage levels also show a distinctive result in Figure10. That blue line represents the normal situation, red line shows the situation of surface damage and the green one shows the situation of heavy damage. The horizontal axis indicates a certain width while the vertical axis states the area of available circulation spaces. The less change is in the different lines, the less damage and danger will come when the earthquake happens.

Area HB (A) has the largest available spaces for each specific width under normal situation and surface damage. Area NM (B) shows little change under all situations. Although the available spaces in area OM (C) are not so abundant, it suffers little decrease under damage. In area TN (E), spaces wider than radius $4.5 \mathrm{~m}$ is hard to find and available spaces over 4 meter declines with a great extent which means that it is almost impossible for fire engines to access when heavy damage comes.

Based on those different features when facing an earthquake disaster in different types of residential area, combining their advantages and disadvantages may improve the condition of a larger scale urban area. The available spaces in High-rise building area can be used as a gathering center for residents of the surrounding area. Streets along Concession area provide dense and protected evacuation routes for the whole region. Going through the yard of the Concession area can upgrade the evacuation efficiency. 

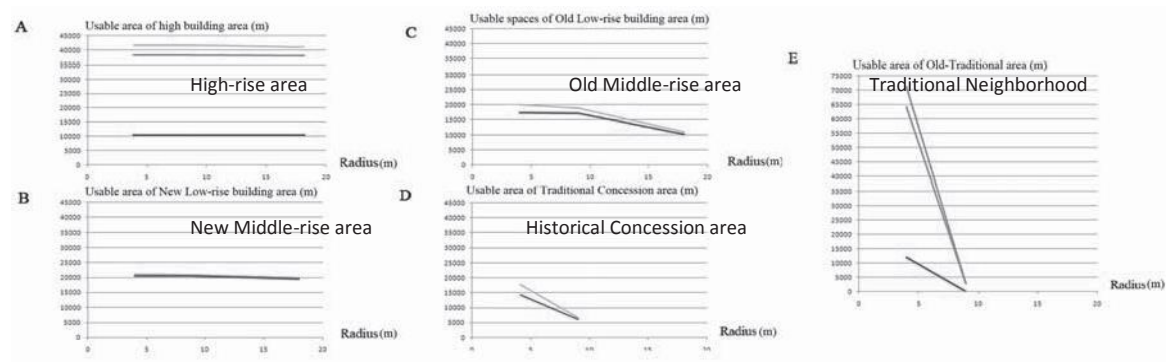

Figure 10: Usable Spaces under Different Damage Situation of Each Area

Source: (Xue Ma, 2011)

\subsection{Conclusion}

Different urban areas possess different physical features which beget different potential vulnerability to the citizens concerning earthquake damages. Thusexamination of vulnerability towards an earthquake resistant residential neighborhood is the first and essential step of setting up an earthquake disaster mitigation system in a Chinese city. Knowing where the weaknesses are gives the direction for optimizing urban spaces in various urban areas. The numerical evaluation results provide us a method for quantification of the degree of vulnerability and tell us what the serious problems might be under different damage situations.

More analysis on the space characteristic is available to help us make a better planning. This analysis method is upgrading into computer programming, it will help us to find out the space data automatically which is more flexible for the space analysis. Based on that, suggestion and planning can be proposed directly in the different urban areas. The same method will be applied again to testify how the circulation spaces improve after the planning.

\section{Acknowledgement}

The author acknowledged support from G-COE Center for Urban Earthquake Engineering (CUEE) in Tokyo institute of Technology for supporting this research. Last but not least, Thanks to Dr. Miura Hiroyuki and Ms. Soh huichen who helped me to process the satellite image.

\section{References}

Asada,T, (2004), Research on the Condition of Disaster Prevention Park Sand it's Directivity in Hiroshima (in Japanese), Architecture Institute of Japan, 27, 737-740.

Gohta, M. (1990), A Morphological Study of Open Space in Urban Space: Part 1 Quantitative Analysis using the 
Ma, X., \& Ohno, R. / Asian Journal of Environment-Behaviour Studies (ajE-Bs), 3(7) Mar / Apr 2018 (p.59-69)

Largest Empty Circle Method (in Japanese), Proceeding of annual conference 1990, 411-412.

Matsuda,N. (2003), Urban Park Planning from the Point of View of the Safe and Secure Urban Environment (in Japanese), Journal of the Japanese Institute of Landscape Architecture, 66(3), 180-184

Oguchi, K. (2003), Parks in Case of Disaster in Tokyo, Construction and Plan of Rescue and Shelter (in Japanese), Journal of the Japanese Institute of Landscape Architecture, 66(3), 208-212.

Tsukada,S. (2008), Analysis of the Evaluation Structure in Design a Ted Manager System of Urban Park, Journal of the Japanese Institute of Landscape Architecture, 73(631), 1923-1928. 